\title{
Properties of Gobi Aggregate and Sulfide-Rich Tailings Cemented Paste Backfill and Its Application in a High-Stress Metal Mine
}

\author{
D. Q. Deng $\mathbb{D}^{1,2}$ Y. H. Liang $\mathbb{D}^{3},^{3}$ and F. C. Huangfu ${ }^{4}$ \\ ${ }^{1}$ School of Civil Engineering and Mechanics, Xiangtan University, Xiangtan, Hunan 411105, China \\ ${ }^{2}$ Institute of Mining Engineering, Guizhou Institute of Technology, Guiyang, Guizhou 550003, China \\ ${ }^{3}$ Planning and Finance Division, Guizhou Institute of Technology, Guiyang, Guizhou 550003, China \\ ${ }^{4}$ Xinjiang Ashele Copper Co., Ltd., Habahe, Altay, Xinjiang 836700, China \\ Correspondence should be addressed to D. Q. Deng; ustbb20070025@126.com and Y. H. Liang; 81036423@qq.com
}

Received 4 January 2021; Revised 21 January 2021; Accepted 30 January 2021; Published 16 February 2021

Academic Editor: Zizheng Zhang

Copyright $\odot 2021$ D. Q. Deng et al. This is an open access article distributed under the Creative Commons Attribution License, which permits unrestricted use, distribution, and reproduction in any medium, provided the original work is properly cited.

\begin{abstract}
This experiment studied the influence law of the strength of CPB affected by tailings content, Gobi aggregate content, cement content, and slurry concentration. The results show, for the CPB with concentration of $77 \%$, when the addition amount of cement reaches $20 \%$, the addition amounts of tailings and Gobi aggregate change within the ranges of 12 24\% and 56 68\%, respectively. The strength of CPB has been gradually improved when the addition amount of Gobi aggregates decreases and the addition amount of tailings increases. In this case, the slump of $\mathrm{CPB}$ changes within the range of $26.5 \mathrm{~cm} \sim 26.9 \mathrm{~cm}$ while the strength of CPB changes within the range of 4.021 6.845 MPa. Considering future utilization value of tailings, the addition amount is finally set at $16 \%$ in production, and the addition amount of Gobi aggregate is set at $64 \%$; namely, tailings: Gobi aggregate $=20: 80$. When the addition amount of cement is $20 \%$ (cement/(tailings + Gobi aggregates) $=1: 4$ ), the strength of CPB reaches $5.62 \mathrm{MPa}$ which meets the production requirement. When the heading machine is used for tunnelling mine roadway in bottom backfill of VCR stope, no collapse or delamination occurs without support, showing good stability and integrity of backfill. When the adjacent stope ore is mined, the backfill with cement content of $11.1 \%, 14.3 \%, 20 \%$, and $25 \%$ is exposed. In the process of mining, no collapse or delamination occurs. Therefore, the proportion of various backfill materials applied in production is reasonable, being verified by the experiment and field test.
\end{abstract}

\section{Introduction}

Over the course of past 20 to 30 years, the China mining has gradually developed tending to stricter and perfect ecoenvironment protection. Especially in recent 10 years, some provinces have introduced corresponding environmental protection policies and regulations in succession, requiring the mining enterprises to have sound tailing disposal systems and preventing the land from collapse. With the development of mining, the strata and rocks show some corresponding mechanical changes and have a certain impact on the stability of rock mass [1-5]. This means that mine enterprises are not only required to build safe and reliable tailing ponds with proper scale, but also required to keep the maximum discharge reduction of the tailings, to remove the hidden dangers including dam break and leakage of tailing ponds. In general, the tailings are discharged to tailing ponds. For mines with less tailings produced, some tailings will be used for the preparation of building materials if tailings meet the requirements of building materials. If the tailings contain some useful minerals, the tailings can be sold to other enterprises for refining useful minerals. Among the tailing disposal methods, the best way is to use tailings as filling material in the underground goaf so as to achieve objectives such as maximum use of tailings, safety and environmental protection of mine, ground pressure controlling, and resource recycling as well as maintaining the sustainable development. In backfilling of underground goaf, a lot of tailings from ore-dressing can be used; in this process, tailing discharge is reduced and the pollution 
discharge cost is decreased. Meanwhile, the backfill plays a great supportive role in the rock strata movement, makes the surrounding rocks in the goaf stabler, and completely restrains the potential damage. Thus, it creates safer environment for surrounding mining, improves the mineral recovery, and reduces the dilution rate of mines simultaneously. Therefore, it contributes to the significant economic and environmental benefits. For deep filling technology in coal mine and roof maintenance in high-stress stope, relevant researchers have done a series of tests and developed a good way of retaining roadway along goaf according to the maintenance of thick and hard roof; it has been used in production, and the mechanism of roof dilatancy and bolt support in filling area of gob-side entry retaining is analyzed [6-9].

The backfill technology of filling the underground goaf with tailings was adopted earlier in foreign countries. In early phase, water and sand were widely used in filling. With the development of technology and equipment, the cemented filling and high concentration paste backfill gradually came into being. The paste backfill presents superior mechanical property in production and plays an important role in recycling resources. By virtue of the advanced pump pressure transport equipment, and strict operation and management mode, the foreign research on the paste backfill technology once took the leading position. The related research is active; for instance, the international paste backfill conference is held regularly once every few years and provides better target and development to the relevant international research. Among these countries, America, Canada, Australia, and South Africa are relatively representative. On preparation and hydrological characteristics of paste tailings, literature illustrates the concentration of sulfide tailings paste as well as field test of LaRonde polymetallic ore in Abitibi, Quebec, and the analysis on mechanics and hydrologic features of cemented and uncemented paste [10]. In addition, there is a study on mixed characteristics of the sulfide tailings backfill and the influence of the mixing and stirring on the mechanical property, which can be referred to by the similar analysis [11], while in literature, the performance of $\mathrm{CPB}$ is predicted and the cost is analyzed, which could be a guidance to production and application [12]. In literature, the paste backfill technology of the underground hard-rock mine is analyzed, the mechanical property of CPB in the stope is studied, the importance of the horizontal stress towards the acting force of backfill is pointed out, and the influence characteristic of the initial concentration of tailings on the paste preparation, shear yield stress, and viscosity of pipeline transport is emphasized. That is of great importance to guide production [13].

Literature shows the strength test on cementing materials of $\mathrm{CPB}$ including the ordinary Portland cement (OPC), Portland composite cement (PCC), and sulphate resistant cement (SRC) separately, presenting the influence of cementing agent type and dosage on the short-term and long-term mechanic performance of $\mathrm{CPB}$, which can be reference for the mine backfill in selecting proper cementing agent [14]. Literature studies the influence of 3 water reducing agents on the rheological property of the paste filling slurry and the mechanical strength of the $\mathrm{CPB}$ and also analyzes the mechanical property of $\mathrm{CPB}$ when the mass percentage of OPC and PCC is $5 \%$, which can be regarded as the design basis of related engineering [15]. The paste backfill technology of Kidd Creek ore is examined and the technical characteristics are analyzed, which is helpful for production [16]. The hydrological property and geomechanics property of $\mathrm{CPB}$ under different curing conditions and stress conditions are investigated, which is quite important for further study on the property of $\mathrm{CPB}$ [17]. With regard to the application of $C P B$ in the ore site of Cayeli, literature measures the mechanics property of $\mathrm{CPB}$, which can provide relative, useful information for safe production [18].

With the development of rock mechanics analysis and testing technology, some new methods and laws have been applied well, and positive results have been obtained, which can be used for reference in filling engineering [19-23]. Among the related research in China, literature shows slump test of paste backfill slurry and analyzes the rheological property of the paste, which could be better basis for the study on the flow and diffusion property of backfill slurry [24]. Literature illustrates a series of tests aiming at the paste backfill of Chihong ore and analyzes the relationship between the solid content of paste backfill slurry and its rheological property as well as mechanical property, which plays a vital role in better application of production [25]. With regard to mining under villages, as tests have shown in the literature, solid wastes are used to prepare backfill $[26,27]$. The strength change of CPB and its influential factors are analyzed. In field application, the high-quality CPB effectively controls the ground pressure, restricts the sinking of the rock stratum, and successfully realizes the target of coal mining without relocating the village. Literature shows application of crude tailings to prepare the CPB that achieves good result in Lame Zinc Mine, in which the paste backfill technology is relatively early applied in Southwest China [28]. The literature analyzes the rheological property of the crude tailings paste slurry and the inspection optimization test of its yield stress, which provides reference for analyzing the pipeline transportation efficiency [29, 30]. Literature states the change and development of the paste backfill and tailing disposal technology, performs fluidity test on the paste prepared by crude tailings and water-quenched slag, and analyzes and optimizes the pumping performance of the paste [31, 32].

At the present stage, because of the influence of labor cost and raw material price, the production cost of filling engineering is rising constantly; in order to reduce the production cost, various related research works also become more and more [33-37]. In the research on slag cementitious materials, some scholars have optimized the slag powder and its properties so that solid waste such as slag can be reused and the environment can be protected, thus laying a foundation for the operation of the filling system [38-42]. For large-scale industrial solid waste treatment, the researchers conducted feasibility analysis on solid waste resource utilization based on laboratory tests. Based on the macroscopic and microscopic characteristic tests, the physicochemical properties of solid waste were optimized to meet the technical requirements of mined-out voids backfilling, thus creating conditions for large-scale industrial treatment of solid waste and effectively protecting the overburden strata of mined-out voids in the area of high in situ stress [43-45]. Based on the method of soil mechanics, 
some researchers have studied the stability of rock mass, the triaxial force of filling body, and the law of stress and strain of filling body, to create the conditions for engineering applications [46-49].

As for the high concentration cemented backfill technology of Gobi aggregate, tailings, and cement, the basic test of the property of backfill material was done based on multiple-material additive technology of Ashele Copper Mine. According to the test result, the study could be used for the guidance of production. As one of the main mines of Fujian Zijin Group, focusing on technical research and development as well as technology innovation, Ashele Copper Mine has already become a typical scientific and technological manufacturer of Zijin Group and even Northwest China with constant development. At present, it has become a large nonferrous mine with mining capacity of $6000 \mathrm{t} / \mathrm{d}$. The mine locates in south hilly land of Altay, the northwestern part of Xinjiang. There, the winter is cold and long with heavy snowfalls. The terrain of the mine is high in north and east with a relative height difference of $30 \sim 50 \mathrm{~cm}$ and maximum height difference of $100 \sim 300 \mathrm{~cm}$, while the southwestern part of the mine is flat, and the relative height difference is about $10 \mathrm{~m}$. Ashele Copper Mine has high copper and zinc grade of $2.46 \%$ and $1.98 \%$, respectively. The subterranean mine is divided into three mining parts: the upper, the middle, and the lower. The ore rock of the upper part is relatively broken, so the downward access method is adopted. While the ore rock of the middle part is relatively better than that of the upper, so the upward slicing is applied. For the lower part with good ore rock conditions, VCR mining method is adopted.

In order to make full use of ore resources, avoid the surface subsidence, and create safe and clean working environment for the borehole operation, the cemented paste backfill is applied in Ashele Copper Mine using Gobi aggregates and tailings as coarse and fine aggregates together with locally produced PC 32.5 composite slag cement as cementing material. The applied Gobi aggregates are produced around the mine. To collect the Gobi aggregates, the surface soil layer of the ancient river bed is peeled off. Then, Gobi aggregates are screened to remove the blocks and fine silts and keep particles with the size of $48-25,000 \mu \mathrm{m}$, while the content of the particles $<48 \mu \mathrm{m}$ is less than $7-12 \%$ according to technical requirements. The tailings for backfill are discharged by ore treatment plant. Some useful substances are contained in tailings and they are difficult to recycle with current ore-dressing technique. Considering the possible use of minerals in future, we discharge most tailings into the tailing pond for stock and piling while only a small amount of tailings is used for underground backfill. During the blending process of backfill, the proportions of the tailings and Gobi aggregates are $30: 70,25: 75,20: 80$, and $15: 85$. Based on the strength test of backfill, the ratio of tailings and Gobi aggregates with best strength performance is $30: 70$. To reduce the use of tailings and meet the strength performance requirement of backfill, the actual proportion of tailings and Gobi aggregates is generally set to $20: 80$ in production. Over 10 years, since the Ashele Cooper mine has been built and put into production, the cemented backfill mining plays an active role in production. Namely, it is of great importance to the stability of rock stratum with rock bump tendency and full recycling of the ore.

\section{Materials and Methods}

2.1. Characteristics of Tailings. The coarse aggregate cemented paste preparation system of Ashele Copper Mine is composed of 2 vertical sand tanks, 2 cement bins, and 2 sets of Gobi aggregate belt conveyer. In the backfill process of paste preparation in station, tailings slurry with the concentration of $26-33 \%$ is transported from the oredressing plant to the vertical sand tanks and material blending house through the pipeline. Gobi aggregates are transported by the forklift to the belt conveyer room. Then, big Gobi aggregate blocks with size of $>25 \mathrm{~mm}$ are removed by screening, while materials with size of $\leq 25 \mathrm{~mm}$ will travel to the material blending house through the belt conveyer. The cement is transported to the material blending house through the spiral conveyer, located at the bottom of cement bin. In the blending material house, the tailings, Gobi aggregates, and cement are put into the mixer after preliminary mixing. After complete stirring in two-stage horizontal mixer, the paste backfill slurry with the concentration of $75-81 \%$ is transported to the goaf for backfill through the backfill pipeline.

Results of the chemical composition analysis for tailings and Gobi aggregates are shown in Table 1. As data show, tailings consist of sulfur (S) accounting for $48 \%$, total iron (TFe) accounting for $43.38 \%, \mathrm{SiO}_{2}$ accounting for $1.77 \%$, phosphorus (P) accounting for $0.0097 \%$, and $\mathrm{Al}_{2} \mathrm{O}_{3}$ and $\mathrm{CaO}$ with $\mathrm{MgO}$ totally accounting for $0.86 \%$. The current mineral processing technology applied in Ashele Copper Mine is fine grinding of the tailings after copper and zinc selection are finished, and then selecting copper and zinc in sequence. In view of low price of $S$ and Fe, the selection of both elements has not been carried out in recent years, and some tailings are used for backfill in the pit. Therefore, the contents of S and $\mathrm{Fe}$ are high in tailings. Furthermore, the content of fine particles in tailings is high after 2 times of grinding. In general, $\mathrm{Fe}$ is favorable for the strength performance of backfill, while the excessive content of $S$ is unfavorable for the strength. Although the contents of S and Fe are high in tailings, there will not be negative impact on the strength of backfill as tailings are only used as auxiliary additives.

As shown in Table 2, the proportion of tailings is 4.39, the loose volume weight and dense volume weight are $1.55 \mathrm{t} /$ $\mathrm{m}^{3}$ and $2.23 \mathrm{t} / \mathrm{m}^{3}$, and the porosity is $49.2 \%$. On the basis of mineral process of Ashele Copper Mine and the chemical composition analysis of tailings, it is known that the relatively high content of Fe leads to the high proportion of tailings. As for loose stack and dense stack, the porosity is relatively big. When tailings are used for backfill, it is easy to form relatively dense backfill. Hence, they are helpful for improving the strength of backfill.

shown in Table 3, the test data indicates that the average particle size of tailings in Ashele Copper Mine is $34.4 \mu \mathrm{m}$, of which the percentage of fines (particle size $<29.6 \mu \mathrm{m})$ is $18.33 \%$ and the content of the particles 
TABLE 1: Chemical composition of tailings and Gobi aggregates.

\begin{tabular}{lccccccc}
\hline \multirow{2}{*}{ Material } & \multicolumn{3}{c}{ Content of chemical composition (\%) } \\
& $\mathrm{SiO}_{2}$ & $\mathrm{Al}_{2} \mathrm{O}_{3}$ & $\mathrm{MgO}$ & $\mathrm{CaO}$ & $\mathrm{S}$ & $\mathrm{P}$ & \multicolumn{2}{c}{$\mathrm{Fe}$} \\
\hline Tailings & 1.77 & 0.44 & 0.06 & 0.36 & 48.0 & 0.0097 \\
Gobi aggregates & 85.61 & 3.92 & 0.41 & 1.91 & 0.095 & 0.013 & 2.06 \\
\hline
\end{tabular}

TABle 2: Physical properties of filling materials.

\begin{tabular}{lccccc}
\hline Material & Proportion & Loose volume weight $\left(\mathrm{t} / \mathrm{m}^{3}\right)$ & Dense volume weight $\left(\mathrm{t} / \mathrm{m}^{3}\right)$ & Porosity $(\%)$ & Slope angle $\left({ }^{\circ}\right)$ \\
\hline Tailings & 4.39 & 1.55 & 2.23 & 49.2 & 41.5 \\
Gobi aggregates & 2.56 & 1.26 & 1.75 & 31.6 & 36 \\
PC32.5 cement & 3.11 & 1.02 & 1.61 & 48.2 & 39 \\
\hline
\end{tabular}

TABle 3: Particle size distribution of tailings and PC32.5 cement.

\begin{tabular}{|c|c|c|c|c|c|c|c|c|c|}
\hline \multirow{2}{*}{ Material } & \multicolumn{9}{|c|}{ Particle size cumulative passing (\%) } \\
\hline & $5 \mu \mathrm{m}$ & $10 \mu \mathrm{m}$ & $20 \mu \mathrm{m}$ & $50 \mu \mathrm{m}$ & $75 \mu \mathrm{m}$ & $100 \mu \mathrm{m}$ & $150 \mu \mathrm{m}$ & $200 \mu \mathrm{m}$ & $300 \mu \mathrm{m}$ \\
\hline Tailings & 4.13 & 9.10 & 18.33 & 82.28 & 99.47 & 100 & 100 & 100 & 100 \\
\hline PC32.5 cement & 14.77 & 28.73 & 48.31 & 81.58 & 92.53 & 97.00 & 99.51 & 99.86 & 100 \\
\hline
\end{tabular}

(particle size $<75 \mu \mathrm{m}$ ) is $99.47 \%$. Compared with that of other mines, the particle size of tailings is really fine, and the content of coarse particles is low. Moreover, the mean particle size of PC32.5 cement used for Ashele Copper Mine backfill is $29.6 \mu \mathrm{m}$, of which the percentage content of the fines (particle size $<20 \mu \mathrm{m}$ ) is $48.31 \%$, while that of particles (particle size $<75 \mu \mathrm{m}$ ) is $92.53 \%$. Compared with tailings of Ashele Copper Mine, the mean particle sizes of cement and tailings are basically of the same order of magnitude. Sufficient superfine cement and tailings particles are necessary for pipeline transportation of coarse aggregate paste slurry.

2.2. Characteristics of Gobi Aggregates. Table 1 shows that the main component of Gobi aggregates is $\mathrm{SiO}_{2}$ accounting for $85.61 \%$, while $\mathrm{S}$ and $\mathrm{Fe}$ are quite low accounting for only $0.095 \%$ and $2.06 \%$, respectively. Besides, the total content of $\mathrm{Al}_{2} \mathrm{O}_{3}, \mathrm{CaO}$, and $\mathrm{MgO}$ accounts for $6.24 \%$, the content of $\mathrm{P}$ is $0.013 \%$, and the content of other chemical compositions is quite low. According to the chemical composition analysis of Gobi aggregates, the content of $\mathrm{SiO}_{2}$ is relatively high in Gobi aggregates. As the content of Gobi aggregates (the most important backfill material) is high, it can be used to make up for insufficient $\mathrm{SiO}_{2}$ and improve the strength of paste backfill.

As shown in Table 2, the proportion of tailings is 2.56, the loose volume weight and dense volume weight are $1.26 \mathrm{t} /$ $\mathrm{m}^{3}$ and $1.75 \mathrm{t} / \mathrm{m}^{3}$, and the porosity is $31.6 \%$. Compared with the backfill of other mines, the proportion and porosity of Gobi aggregates are both small relatively. When used as the backfill, they can match well the physical and mechanical property of tailings. When the tailings particles are filled in the Gobi aggregates, it is easy to form stable mechanical structure, which is helpful for mechanical property of the backfill.
As shown in Table 4, the particle size of Gobi aggregates, the maximum particle size of Gobi aggregates for backfill of Ashele Copper Mine is $25000 \mu \mathrm{m}$, of which the proportion of fines (particle size $<20 \mu \mathrm{m}$ ) is $9.74 \%$, and that of the particles $(<1,000 \mu \mathrm{m},<2,000 \mu \mathrm{m}$, and $<10,000 \mu \mathrm{m})$ is $59.45 \%, 64.26 \%$, and $88.46 \%$, respectively. Thus, the particle sizes of Gobi aggregates, tailings, and PC32.5 cement are not of the same order of magnitude. The Gobi aggregates are coarse, which can well match the fine particles and is helpful for improving the gradation of the backfill.

2.3. Cementing Agent. Generally, the cement is widely used as cementing material in mines. For the filling project of high-stress underground GOAF in Ashele Copper Mine, the way to obtain cement is convenient because of the good highway traffic condition in the enterprise's geographical location; therefore, on the premise of obtaining good mechanical properties of paste filling materials, the price of PC32.5 cement is also cheaper than that of PO 42.5 cement and slag cement; the filling cementitious material was determined to be of grade PC32.5 cement produced by a nearby cement plant. Owing to small particle size, some cement in the mixing material together with slurry of other particles can form argillaceous layer during the process of backfill slurry pipeline transportation. When the paste flows in the pipeline, the argillaceous layer can lubricate the inner wall of pipeline. This greatly helps to reduce the transportation resistance and makes the paste backfill slurry stably flow with high concentration. Locally produced PC32.5 cement is used as backfill cementing agent in Ashele Copper Mine. As data of Table 2 show, the proportion of PC32.5 cement is 3.11, the loose volume weight and dense volume weight are $1.02 \mathrm{t} / \mathrm{m}^{3}$ and $1.61 \mathrm{t} / \mathrm{m}^{3}$, and the porosity is $48.2 \%$. 
TABle 4: Particle size distribution of the Gobi aggregates.

\begin{tabular}{lcccccc}
\hline Particle size $(\mu \mathrm{m})$ & 5 & 20 & 75 & 200 & 500 & 1000 \\
\hline Accumulative passing (\%) & 2.089 & 9.74 & 19.67 & 27.71 & 44.97 & 59.45 \\
Particle size $(\mu \mathrm{m})$ & 2500 & 5000 & 8000 & 10000 & 12000 & 14000 \\
Accumulative passing (\%) & 64.77 & 80.75 & 85.48 & 88.46 & 91.75 & 94.08 \\
\hline
\end{tabular}

The cement can be used not only as a cementing agent but also as fine particle backfill. Like tailings particles, the cement particles are evenly distributed in the gap of Gobi aggregates particles. The cementation of cement consolidates tailings and Gobi aggregates as a whole, forms the even distribution structure of coarse and fine particles, and finally constitutes a relatively stable mechanical structure. That is the reason why coarse aggregates particles are added to the backfill, resulting in higher strength compared with the cemented tailings backfill.

2.4. Water. The tap water is used to mix the cementing agents, tailings, and Gobi aggregates uniformly. The amount of water is determined by the concentration of paste backfill slurry that needs to be prepared.

2.5. Preparation of the Paste Backfill. In practical application, when the paste preparation concentration is low, such as $75 \%$ or $77 \%$, the coarse aggregate in the paste will be faster than the previous sedimentation rate, but there is no serious stratification or segregation, and the way to overcome the rapid sedimentation rate of coarse aggregate in paste is to increase the flow rate properly to ensure that the paste can continue to advance steadily under high pipe pressure. According to the concentration of the paste backfill slurry in field investigation and actual production, the factors influencing the strength of backfill are analyzed. As the result shows, the content of cementing agents, the proportion of tailings and Gobi aggregates, and slurry concentration have significant influence on the strength performance of backfill. Thus, the proportions of tailings and Gobi aggregates are 30 : $70,25: 75,20: 80$, and $15: 85$. The proportions for the cement/(tailings + Gobi aggregates) are 1:3, 1:4, 1:6, 1:8, and $1: 10$. To make the paste backfill test specimens with the concentration of $75 \sim 83 \%$, mix the tailings, Gobi aggregates, and PC32.5 cement with a certain proportion; add water; and mix them uniformly. Then, pour the uniformly mixed paste backfill slurry into the steel tool with specification of $7.07 \mathrm{~cm}^{3}$. (After the tool is disassembled, the volume of specimen is $7.07 \mathrm{~cm}^{3}$.) Then put the test specimen into conservation cabinet with constant temperature and humidity, and test its uniaxial comprehensive strength on the $3^{\text {rd }}, 7^{\text {th }}, 28^{\text {th }}$, and $60^{\text {th }}$ days, respectively.

2.6. Mechanical Test. Generally, in underground mining, it is necessary to test the independence of the disclosed backfill after the adjacent ores in the stope are mined. This means that the unconfined compressive strength of the backfill, namely, uniaxial compressive strength, needs to be tested. In this experiment, the uniaxial compressive strength of the backfill is tested by NYL-300 press machine, which is equipped with microprocessor control and record system. Two relatively flat opposites are selected as compression faces for the test, and the regulation together with loading is carried by the pressure sensor. By controlling the loading with the displacement at the speed of $1.5-2 \mathrm{~mm} / \mathrm{min}$, the uniaxial compressive strength is recorded till the test specimen is damaged, the stress is no longer increased, and press machine stops loading automatically. Thus, the final value is the average value of data while the uniaxial compressive strength of all backfill can be recorded and kept by the testing system.

\section{Results}

3.1. Effect of Tailings Content on the Strength of CPB. The specimens of the first group are used to study the influence of tailings content on the strength of CPB. The concentration is $77 \%$, the proportion of cement/(tailings + Gobi aggregates) is $1: 4$; the proportion of tailings and Gobi aggregates is $5: 85,20: 80,25: 75$, and $30: 70$, respectively. Namely, in the dried materials without water, the percentage content of cement is $20 \%$ all along while that of Gobi aggregates is $68 \%, 64 \%, 60 \%$, and $56 \%$, respectively; the percentage content of tailings is $12 \%$, $16 \%, 20 \%$, and $24 \%$, respectively. Figure 1 -the curve of the effect of the tailings content on the strength of $\mathrm{CPB}$ - shows the rule that the strength of the CPB changes with the percentage content of tailings. Based on the slump test, it is known the slump of the above four types of paste backfill slurry changes from $26.9 \mathrm{~cm}$ to $26.5 \mathrm{~cm}$ with increasing of tailings and decreasing of Gobi aggregates. This means that the more the tailings (as fine particles) added, the more the water that can be absorbed by the paste to reduce the slump of backfill slurry. As Figure 1 shows, the strength of the CPB specimen in different curing periods is increased along with the increase in tailings addition correspondingly. The strength amplification of the specimen with curing period of 3 days and 7 days is relatively small. Along the extension of the curing period, when it reaches 28 days and 60 days, the strength amplification of the specimen increases greatly. This indicates that, in a certain range, the addition of tailings is helpful to improve the strength of the specimen. As the tailings particles are relatively fine, they can be uniformly dispersed in the gap of Gobi aggregates with coarse particles and form dense structure. When affected by the external force, the coarse particles are not easy to dislocate. If there are more tailings particles with the percentage content of tailings reaching $20 \%$ and $24 \%$, the particles of Gobi aggregates will be more tightly encapsulated. Therefore, macroscopically, this shows that 


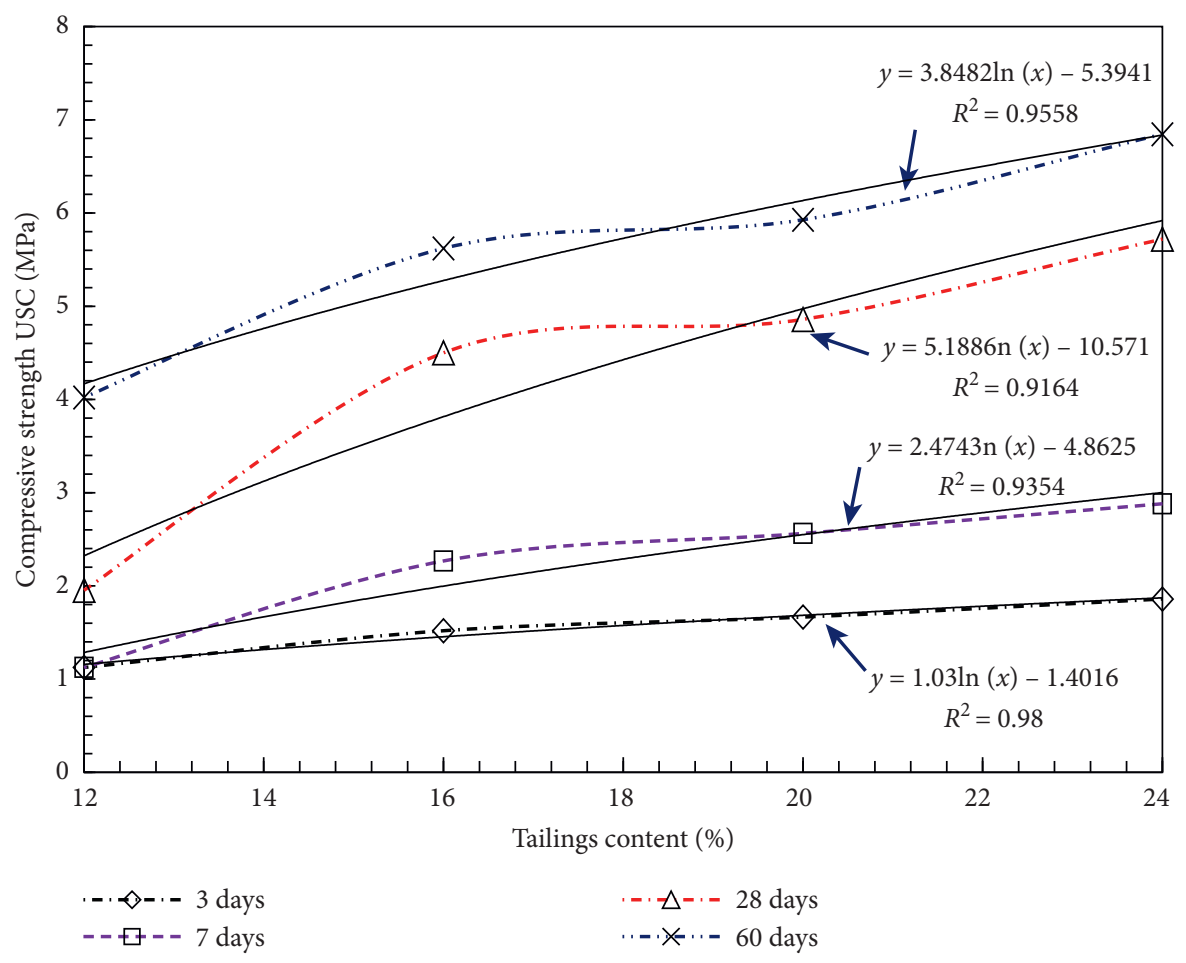

FIgURE 1: Effect of the tailings content on the strength of CPB.

the specimens have relatively high uniaxial comprehensive strength.

According to the data and the trend of the curve, we analyze the change of paste filling strength with the tailings content, use statistical software for fitting test curve, and can get relations between tailings content $(x)$ and paste filling strength $(y)$. From Figure 2, we can see that the correlation coefficient is $0.9164 \sim 0.98$ when the logarithm character is used to describe the effect of the tailings content on the strength of the paste filling body at times of $3 \mathrm{~d}, 7 \mathrm{~d}, 28 \mathrm{~d}$, and $60 \mathrm{~d}$, which shows that the fitting effect is good, meeting the requirements. The common logarithmic expression is shown in (1), and the coefficient $a_{1}, b_{1}$ ranges are shown in Figure 1.

$$
y=a_{1} * \ln (x)-b_{1} \text {. }
$$

3.2. Effect of the Gobi Aggregates Content on the Strength of $C P B$. To study the effect of Gobi aggregates content on the strength of $\mathrm{CPB}$, the specimens of the first group with the proportion and content of all materials as mentioned above are analyzed. The percentage content of Gobi aggregates is $56 \%$, $60 \%, 64 \%$, and $68 \%$, respectively. Figure 2-the effect of Gobi aggregates content on the strength of $\mathrm{PCB}$ - shows the rule that the strength of $\mathrm{CPB}$ changes with the change of Gobi aggregate content. As shown in Figure 2, as Gobi aggregates addition increases, the strength of CPB specimens in different curing periods decreases. The amplification of the test specimens with curing periods of 3 days and 7 days is relatively small. With the extension of the curing period, when it reaches 28 days and 60 days, the strength of the specimen increases rapidly. This indicates that, in a certain range, the addition of Gobi aggregates is unfavorable for the strength of the specimens. As Gobi aggregates particles are relatively coarse, proper addition of Gobi aggregates can improve the mechanical structure of particles in the backfill as well as the strength of CPB. However, with increase of addition, the structure will become relatively loose with less density due to the lack of fine particles to backfill the gap between the particles of Gobi aggregates. When affected by the external force, the coarse particles of Gobi aggregates will be dislocated mutually owing to the lack of fine particles for encapsulating. When the percentage content of Gobi aggregates reaches $64 \%$ and $68 \%$, with relatively big external force, the fine particles cannot form dense structure to maintain the stability of the coarse particles of Gobi aggregates. Therefore, macroscopically, this shows that the specimens have relatively weak uniaxial comprehensive strength.

According to the data and the trend of the curve, we analyze the law of the paste filling body strength with the Gobi content changes. By using statistical software and getting fitting test curve, it is easy to get relationship between Gobi aggregate content $(x)$ and paste filling body strength $(y)$. It can be seen from Figure 3 that the correlation coefficient ranges from 0.954 to 0.9849 when quadratic polynomials are used to characterize the effect of Gobi aggregate content on the strength of paste filling body at times of $3 \mathrm{~d}, 7 \mathrm{~d}, 28 \mathrm{~d}$, and $60 \mathrm{~d}$, which means that the fitting 


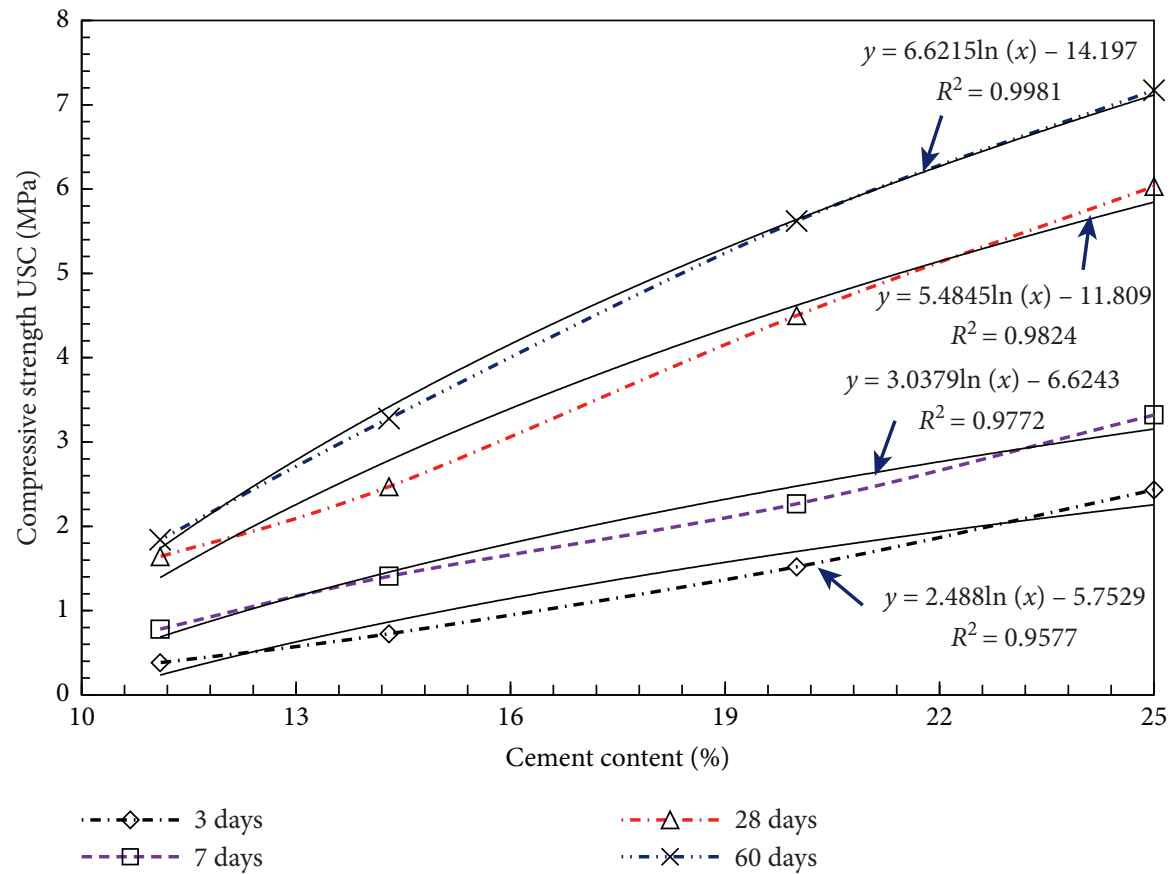

Figure 2: Effect of cement content on the strength of CPB.

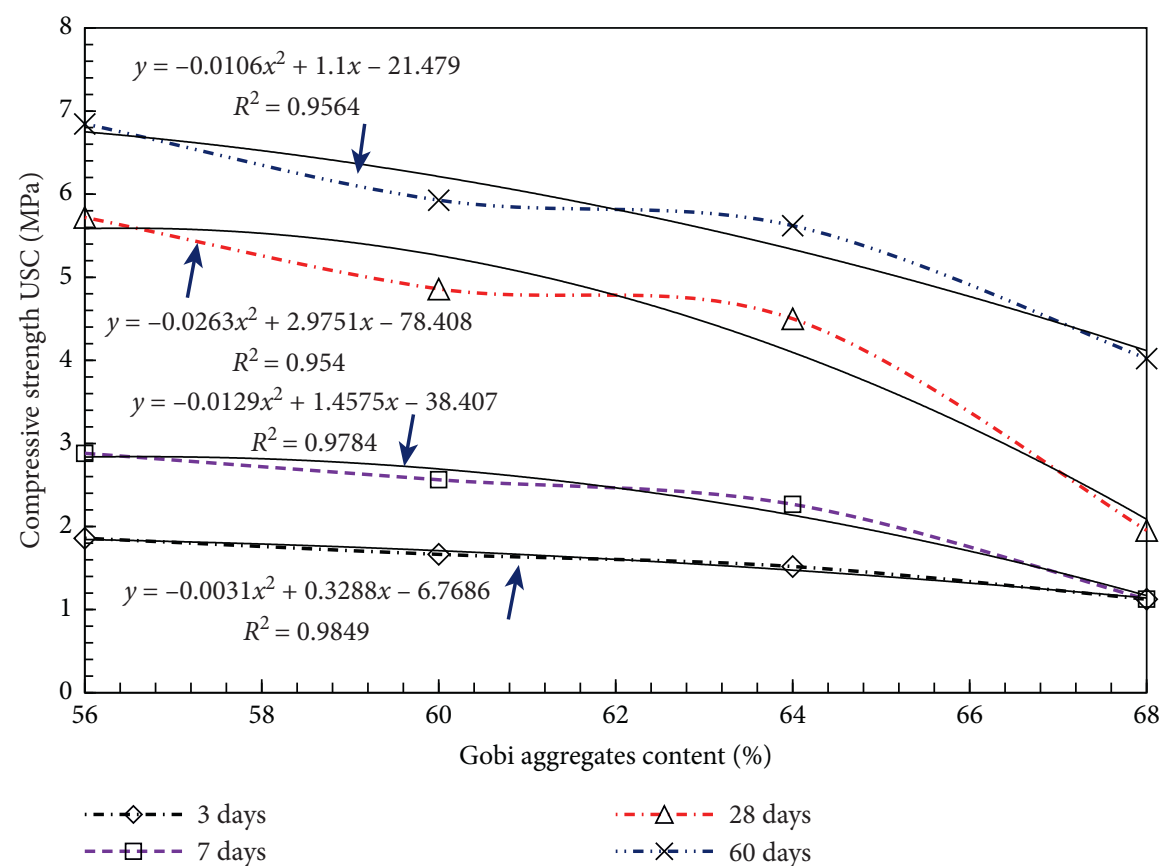

FIgURE 3: Effect of the Gobi aggregates content on the strength of CPB.

effect is good. The common expression is shown in (2), and the coefficients ranges of $a_{2}, b_{2}, c_{2}$ are shown in Figure 2.

$$
y=-a_{2} * x^{2}+b_{2} * x-c_{2} \text {. }
$$

3.3. Effect of the Cement Content on the Strength of CPB. The specimens of the second group are used to study the effect of cement content on the strength of CPB. The concentration is $77 \%$, the proportion of tailings and Gobi aggregates is $20: 80$, and the proportion of cement/(tailings + Gobi aggregates) is $1: 3,1: 4,1: 6$, and $1: 8$, respectively. Namely, in the dried materials without water, the percentage content of tailings is $17.8 \%, 17.1 \%, 16 \%$, and $15 \%$ while that of Gobi aggregates is $71.1 \%, 68.6 \%, 64 \%$, and $60 \%$, respectively; the percentage content of cement is $11.1 \%$, $14.3 \%, 20 \%$, and $25 \%$, respectively. The curve of Figure 3-the effect of the cement content on the strength of 
$\mathrm{CPB}$ - shows the rule that the strength of $\mathrm{CPB}$ changes with the percentage content of cement.

Based on the slump test, it is known the slump of the above four types of paste backfill slurry changes from $26.2 \mathrm{~cm}$ to $26.9 \mathrm{~cm}$ with the increase of tailings and decrease of Gobi aggregates. This means that the more the cement (as fine particles) added, the more the water that can be absorbed by the paste to reduce the slump of backfill slurry. As Figure 3 shows, the strength of the $\mathrm{CPB}$ specimen in different curing periods is increased with the increase of cement addition correspondingly. The strength amplification of the specimen with curing period of 3 days, 7 days, 28 days, and 60 days is relatively small with low cement content of $11.1 \%$ and $14.3 \%$. With the increase of cement content reaching $20 \%$ or $25 \%$, the strength amplification of the specimen increases greatly. This indicates that, in a certain range, the addition of cement is helpful to improve the strength of the specimen. As the cement particles are relatively fine, they can be uniformly dispersed in the gap of Gobi aggregates with coarse particles and form dense structure. The more the cement added, the more tighter the connection between coarse and fine particles. The coarse particles are not easy to dislocate even when affected by the external force. Therefore, macroscopically, this shows that the specimens have relatively high uniaxial comprehensive strength.

According to the trend of data and curves, we analyze the law of paste filling strength with the change of cement content. By using statistical software, we get fitting test curve, and it is easy to get the function relation between cement content $(x)$ and paste filling body strength $(y)$. From Figure 3, we know that when the logarithmic function is used to characterize the effect of cement content on the strength of paste filling body at times of $3 \mathrm{~d}, 7 \mathrm{~d}, 28 \mathrm{~d}$, and $60 \mathrm{~d}$, the correlation coefficients range from 0.9577 to 0.9981 , which indicates that the fitting effect is good and the accuracy meets the requirements. The logarithmic function expression is expressed by (3), and the range of the coefficients $a_{3}, b_{3}$ is shown in Figure 2.

$$
y=a_{3} * \ln (x)-b_{3} .
$$

3.4. Effect of the Slurry Concentration on the Strength of CPB. The specimens of the third group are used to study the effect of slurry concentration on the strength of $\mathrm{CPB}$. The proportion of cement/(tailings + Gobi aggregates) is $1: 6$, and the proportion of tailings and Gobi aggregates is $20: 80$. The slurry concentration is $75 \%, 77 \%, 79 \%, 81 \%$, and $83 \%$, respectively. The curves in Figure 4-the effect of the slurry concentration on the strength of $\mathrm{CPB}$-show the rule that the strength of the $\mathrm{CPB}$ changes with the slurry concentration. As the result of the slump test shows, the slump of the above four types of paste backfill slurry decreases from $27.5 \mathrm{~cm}$ to $24.5 \mathrm{~cm}$ with the increase of the slurry concentration. This shows that the decrease of water addition leads to the decrease of the water contained in the paste, increase of the viscidity, weak liquidity, and relatively small slump. As Figure 4 shows, with the increase of the concentration, the strength of $\mathrm{CPB}$ specimens in different curing periods is improved correspondingly. When the concentration is $75 \%$ or $77 \%$, the strength of the specimens in different curing periods increases slowly. With the increase of the concentration, reaching $79 \%, 81 \%$, and $83 \%$, the strength of the specimens increases rapidly. With the slope increase of curve, shown in Figure 4, in a certain range, there is a proportional relation between the specimen strength and slurry concentration. In other words, the strength of the specimen increases with the increase of content of solid material. On the other hand, from the micro perspective, when the concentration is relatively low, the backfill formed by the solidification of the backfill slurry contains much water that occupies space. When some free water leaves the backfill, the space will become tiny holes. Compared with the backfill with high concentration, the backfill specimens with low concentration have relatively more tiny holes. This leads to low volume weight. Because of loose connection between coarse particles, there is big compressibility and the integrity is easy to damage when affected by the external force. Macroscopically, the higher the concentration of the slurry is, the higher the uniaxial compressive strength of the specimens will be.

According to the data and the trend of the curve, we analyze the law of paste filling strength with the filling slurry concentration change. By using statistical software, we get fitting test curve, and it is easy to get the function relation between paste concentration $(x)$ and paste filling body strength $(y)$. It can be seen from Figure 4 that when the linear function is used to characterize the effect of filling slurry concentration on the strength of paste filling bodies at times of $3 \mathrm{~d}, 7 \mathrm{~d}, 28 \mathrm{~d}$, and $60 \mathrm{~d}$, the correlation coefficients range from 0.9777 to 0.9959 , which indicates that the fitting effect is good. The function expression is expressed by (4), and the range of coefficients $a_{4}, b_{4}$ is shown in Figure 4 .

$$
y=a_{4} * x-b_{4} \text {. }
$$

\section{Application of Paste Backfill in Production}

In production of Ashele Copper Mine, the tailings, Gobi aggregates, and cement are premixed by horizontal mixer in the first phase and discharged through discharge outlet into the second-phase horizontal mixer for intensive mixing. Then, the paste backfill slurry with better homogeneity and high viscidity is ready, presenting the significant characteristics of the paste. During the preparation of paste filling slurry, when the concentration of paste reaches $81 \%$ or so, the paste will become more viscous, and sometimes it will adhere to the surface of the mixing equipment and the flowing parts, resulting in scaling, thus affecting the normal production. In this process, paste preparation station is usually equipped with production inspectors, using tools such as high-pressure water gun or drill rod, cleaning up the paste materials bonded on the equipment in time to enable the normal operation of the relevant equipment. The uniform paste backfill slurry is transported into the drilling hopper after screening and then sent to the goaf for backfill through the borehole and underground backfill pipeline. 


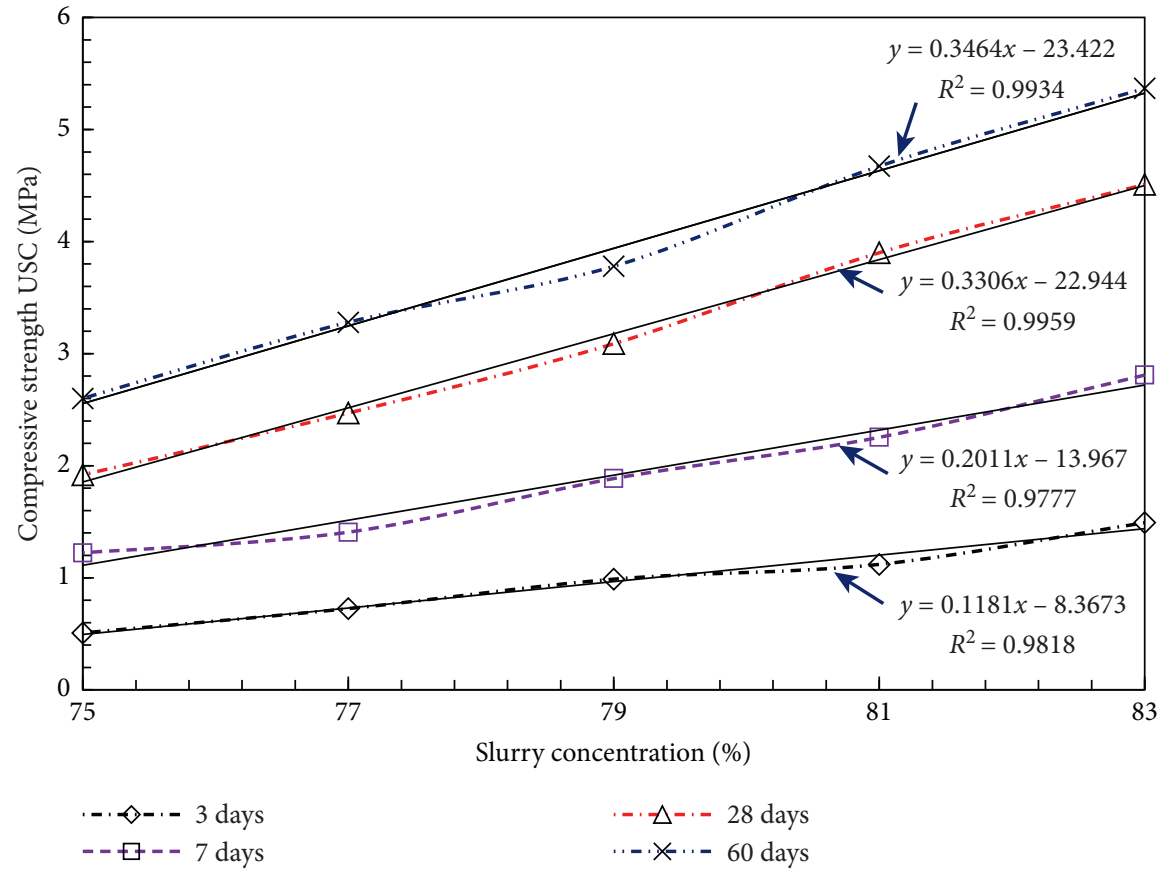

FIGURE 4: Effect of the slurry concentration on the strength of CPB.

Figure 5 shows the preparation process of the paste backfill slurry with Gobi aggregates as the main component. The paste backfill slurry in mushy state shows good performance. Figure 6 shows the status of paste backfill slurry in the boreholes after screening.

As the paste backfill slurry of Ashele Copper Mine has high concentration and little water content, the dehydration is unnecessary after it enters into the stope. Therefore, there is no need to install the filter in stope and decrease the backfill cost. In general, the water in the backfill slurry can be consumed in two ways. First, the hydration of cement can consume some water that exists in the form of molecule bound water. Meanwhile, the water inside the backfill is generally kept for a long time if it is not high or dry. Second, some water is derived from fractures of the ore rock; namely, we can use the fracture and boreholes in the ore rock as the channel and enable the ore rock to absorb some free water.

The paste backfill slurry of Ashele Copper Mine contains less water. Besides, there is little underground water, so it is dry. Therefore, when the slurry enters into the stope, some water is rapidly absorbed by the ore rock. Therefore, the concentration of the paste backfill slurry increases. The solidification and hardening of the paste in stope are faster than those in the laboratory. The strength of the backfill increases rapidly. In general, on the second day after backfill, the backfill surface has relatively high strength. Regarding the stope of Ashele Copper Mine with VCR mining, the paste [cement/(tailings + Gobi aggregates) $=1: 4]$ is used at the bottom, the paste [the cement/(tailings + Gobi aggregates) $=1: 4,1: 6$, and $1: 8]$ is used in the middle part. Before mining the ore pillar in the second step, it is necessary to excavate the tunnels at the bottom of the backfill in the ore house. This requires the backfill to have high strength to prevent the backfill from collapse when excavating tunnels

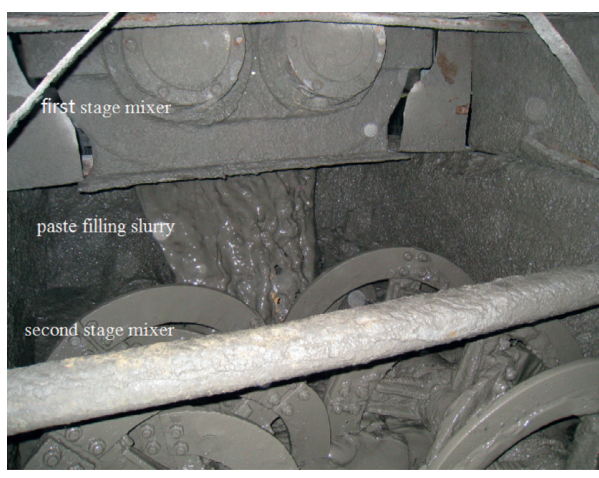

FIGURE 5: Preparation of paste filling slurry.

in the paste backfill ([cement/(tailings + Gobi aggregates) $]=$ $1: 4)$. During excavating tunnels in the backfill, the backfill has good integrity. The cross section of the tunnel is regular. The back and both sides of backfill have dense structures without any loosing or delaminating. When the backfill around the roadway is beaten by the rock, the echo is clear, and the mechanic performance is good. The tunnel excavating process inside the big backfill by heading machine is shown in Figure 7. As we can see, the ore removal roadway formed by excavating has good and complete structure. The imprinting grinded by the cone of the heading machine is clearly distributed in the roof and both sides, indicating good strength and integrity of backfill. Figure 8 shows the status of tunnel after excavation.

From Figures 7 and 8 and long-term observation in the field, it can be seen that the performance of paste filling material can keep stable for a long time in the later period of use, and with the extension of time, the strength of the exposed paste also increased to a certain extent. During the 


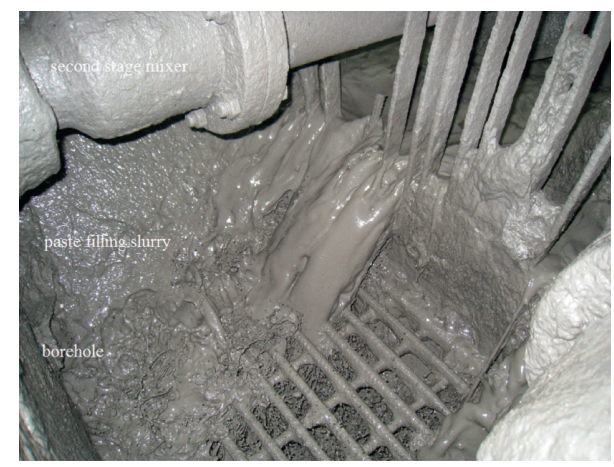

Figure 6: Paste filling slurry flowing into borehole.

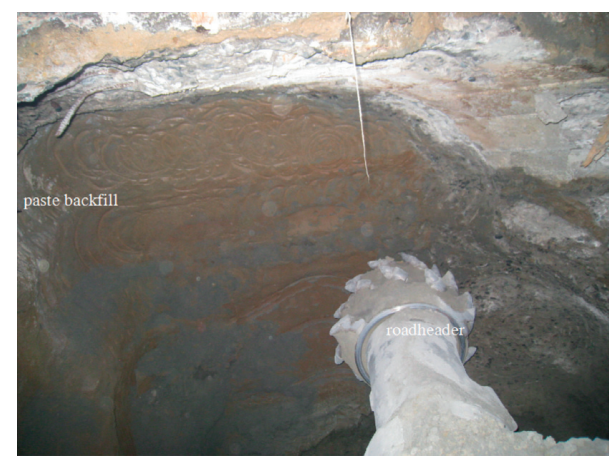

Figure 7: Excavating tunnel in paste backfill.

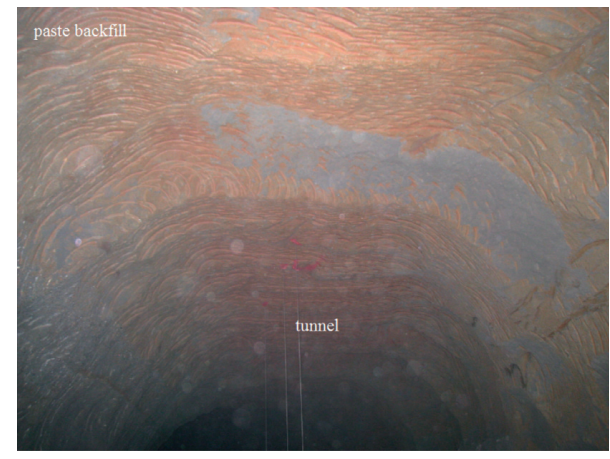

Figure 8: Completed tunnel in paste backfill.

course of transporting ore by LHD, the paste did not collapse and fall. As the performance of paste filling material is uniform, the high stress in the stratum has not destroyed the paste filling material. From the surface of the roadway in the paste, it can be seen that after the extrusion of the roadheader, the surface of the paste has been squeezed more densely, as if a layer of thick crust is formed, with basically no cracks, so the high-stress areas of the tunnel provided a better protection.

\section{Conclusion}

Ashele Copper Mine is the first copper mine that successfully uses Gobi aggregates with coarse particles as main composition to prepare the paste in China. As Ashele Copper Mine has rich Gobi aggregates, they are convenient to get with low price which creates conditions for effective utilization. In general, adding proper coarse materials can not only improve the size grading combination of backfill, but also promote the strength of backfill. Adding proper tailings is favorable for preparing paste with good performance, reducing the abrasion on the pipeline, improving the strength of backfill, and forming dense and stable structure. This helps to maintain mechanical framework of inner particles in backfill and provides safe environment for production. Even though we have achieved success by using Gobi aggregates with coarse particles as main composition to prepare the backfill, Ashele Copper Mine still faces challenges in other aspects. For instance, when we use the coarse aggregate to prepare the backfill slurry, the bend is quite easy to wear, and the cost of pipeline maintenance and change is relatively high. The abrasion on the pipeline can be reduced with more tailings, which has negative impact on the strength of $\mathrm{CPB}$.

In the process of preparing paste with coarse aggregate, it is very important to prevent the deposition and segregation of the granular materials in the paste, which often restricts the daily production schedule. In view of the effect of using tailings with high sulfur and iron content as filling materials to prepare cemented paste filling materials, in the process of large-scale underground mining in Ashele Copper Mine, the self-supporting ability of paste filling materials is better, there is no collapse or flake falling and, the proportion of all kinds of filling materials used in production is reasonable through test and field verification.

This research reveals the rule about the effect of tailings content, Gobi aggregates content, cement content, and slurry concentration on the strength of CPB. As the results show, when the addition amount of Gobi aggregates is within $56 \% \sim 68 \%$, the strength of CPB tends to decrease as addition amount of Gobi aggregates increases. When the addition amount of tailings is within the range of $12 \% \sim 24 \%$, the strength of CPB increases with the increase of tailings. The addition of both backfill materials plays different roles in maintaining the pipeline. As tailings of Ashele Copper Mine are valuable in use, under the premise of ensuring the strength of $\mathrm{CPB}$, it is suggested that tailings are used as backfill material as little as possible. Even though the backfill with good performance is formed when the proportion of tailings and Gobi aggregates is 30:70, the proportion for both materials is finally confirmed at 20:80 in production in consideration of the usage value of tailings. When the addition amount of cement is $20 \%$ [cement/(tailings + Gobi aggregates) $=1: 4]$ and the concentration is $77 \%$, the strength of $\mathrm{CPB}$ reaches $5.62 \mathrm{MPa}$. According to tunnels excavating by heading machine in the backfill at the bottom of VCR stope, the backfill [cement/(tailings + Gobi aggregates) $=1: 4$ ] has good stability and integrity. No collapse or delamination occurs even without support in roadway. When the ores of adjacent stopes are mined, the backfill with cement content of $11.1 \%, 14.3 \%, 20 \%$, and $25 \%$ is exposed. During the whole mining process, no collapse or delamination occurs presenting good independence of the backfill. Therefore, 
the proportion of the backfill used in production is rational according to the test and field validation.

\section{Data Availability}

The data used to support the findings of this study are available from the corresponding author upon request.

\section{Conflicts of Interest}

The authors declare no conflicts of interest.

\section{Authors' Contributions}

D. Q. Deng wrote the main text of the manuscript. Y. H. Liang and F. C. Huangfu collected and analyzed the data. All authors reviewed and commented on the manuscript.

\section{Acknowledgments}

The authors gratefully acknowledge the support for this research from the National Natural Science Foundation of China (51764009), the Guizhou Province Science and Technology Support Plan Project (Grant No. [2018]2836), the Scientific Research Fund of Hunan Province Education Department (20A475), and the High-level Talent Gathering Project in Hunan Province (2019RS1059).

\section{References}

[1] Y. Zhao, Y. Wang, W. Wang, L. Tang, Q. Liu, and G. Cheng, "Modeling of rheological fracture behavior of rock cracks subjected to hydraulic pressure and far field stresses," Theoretical and Applied Fracture Mechanics, vol. 101, pp. 59-66, 2019.

[2] Y. L. Zhao, L. Y. Zhang, J. Liao, W. J. Wang, Q. Liu, and L. Tang, "Experimental study of fracture toughness and subcritical crack growth of three rocks under different environments," International Journal of Geomechanics, vol. 20, no. 8, Article ID 04020128, 2020.

[3] W. Yu, G. Wu, and B. An, "Investigations of support failure and combined support for soft and fractured coal-rock tunnel in tectonic belt," Geotechnical and Geological Engineering, vol. 36, no. 6, 2018.

[4] W. Yu, W. Wang, G. Wu, X. Yu, and W. Peng, "Three zones and support technique for large section incline shaft crossing goaf," Geotechnical and Geological Engineering, vol. 35, no. 5, pp. 1921-1931, 2017.

[5] Y. L. Zhao, L. Y. Zhang, W. J. Wang, Q. Liu, L. M. Tang, and G. Cheng, "Experimental study on shear behavior and a revised shear strength model for infilled rock joints," International Journal of Geomechanics, vol. 20, no. 9, Article ID 04020141, 2020.

[6] Z. Zhang, W. Wang, S. Li, and X. Yu, "Analysis on rockbolt support interaction with roof dilatancy above roadside backfill area in gob-side entry retaining," Geotechnical and Geological Engineering, vol. 36, no. 4, pp. 2577-2591, 2018.

[7] X. Wang, R. Wang, and Z. Zhang, "Numerical analysis method of shear properties of infilled joints under constant normal stiffness condition," Advances in Civil Engineering, vol. 2018, p. 13, 2018.
[8] Z. Zhang, W. Wang, S. Li et al., "An innovative approach for gob-side entry retaining with thick and hard roof: a case study," Technical Gazette, vol. 25, no. 4, pp. 1028-1036, 2018.

[9] W. J. Yu, S. H. Du, and W. J. Wang, "Prediction of instability and mechanism of multi-factor comprehensive action on mine goaf," International Journal of Engineering Research in Africa, vol. 13, no. 2, pp. 39-48, 2014.

[10] E. Yilmaz, M. Benzaazoua, B. Bussière, and S. Pouliot, "Influence of disposal configurations on hydrogeological behaviour of sulphidic paste tailings: a field experimental study," International Journal of Mineral Processing, vol. 131, no. 131, pp. 12-25, 2014.

[11] M. Benzaazoua, T. Belem, and B. Bussière, "Chemical factors that influence the performance of mine sulphidic paste backfill," Cement and Concrete Research, vol. 32, no. 7, pp. 1133-1144, 2002.

[12] M. Fall and M. Benzaazoua, "Advances in predicting performance properties and cost of paste backfill," in Proceedings of the On Tailings and Mine Waste'03, pp. 73-85, Vail, CO, USA, October 2003.

[13] T. Belem and M. Benzaazoua, "Design and application of underground mine paste backfill technology," Geotechnical and Geological Engineering, vol. 26, no. 2, pp. 147-174, 2008.

[14] B. Ercikdi, A. Kesimal, F. Cihangir, H. Deveci, and I. Alp, "Cemented paste backfill of sulphide-rich tailings:importance of binder type and dosage," Cement Concrete Composites, vol. 31, no. 1, pp. 268-274, 2009.

[15] B. Ercikdi, F. Cihangir, A. Kesimal, H. Deveci, and I. Alp, "Utilization of water-reducing admixtures in cemented paste backfill of sulphide-rich mill tailings," Journal of Hazardous Materials, vol. 179, no. 1-3, 2010.

[16] D. A. Landriault, R. E. Brown, and D. Counter, "Paste backfill study for deep mining at Kidd creek," CIM Bulletin, vol. 93, no. 1036, pp. p156-161, 2000.

[17] E. Yilmaz, T. Belem, and M. Benzaazoua, "Effects of curing and stress conditions on hydromechanical, geotechnical and geochemical properties of cemented paste backfill," Engineering Geology, vol. 168, pp. 23-37, 2014.

[18] B. D. Thompson, W. F. Bawden, and M. W. Grabinsky, "In situ measurements of cemented paste backfill at the Cayeli mine," Canadian Geotechnical Journal, vol. 49, no. 7, pp. 755-772, 2012.

[19] Y. L. Zhao, C. S. Zhang, Y. X. Wang, and H. Lin, "Shearrelated roughness classification and strength model of natural rock joint based on fuzzy comprehensive evaluation," International Journal of Rock Mechanics and Mining Sciences, vol. 137, Article ID 104550, 2020.

[20] Y. Zhao, C. L. Wang, and J. Bi, "Analysis of fractured rock permeability evolution under unloading conditions by the model of elastoplastic contact between rough surfaces," Rock Mechanics and Rock Engineering, vol. 53, 2020.

[21] R. Rankine, M. Pacheco, and N. Sivakugan, "Underground mining with backfills," Soils and Rocks, vol. 30, no. 2, pp. 93-101, 2007.

[22] M. Fall, M. Benzaazoua, and E. G. Saa, "Mix proportioning of underground cemented tailings backfill," Tunnelling and Underground Space Technology, vol. 23, no. 1, pp. 80-90, 2008.

[23] B. Tikov and B. Mostafa, "Design and application of underground mine paste backfill technology," Geotechnical and Geological Engineering, vol. 26, no. 2, pp. 147-174, 2008.

[24] J. Zhao and L. Liu, "Research into rheological properties of backfill paste based on the slump test," Journal of Xi'an University of Architecture \& Technology (Natural Science Edition), vol. 47, no. 2, 2015. 
[25] S. Yin, A. Wu, K. Hua, Y. Wang, and Y. Zhang, "The effect of solid components on the rheological and mechanical properties of cemented paste backfill," Minerals Engineering, vol. 35, pp. 61-66, 2012.

[26] H. Zhou, C. Hou, X. Sun, Q. Qu, and D. Chen, "Solid waste paste filling for none-village-relocation coal mining," Journal of China University of Mining \& Technology, vol. 33, no. 2, pp. 154-158, 2004.

[27] C. Zhao, H. Zhou, J. Bai, Q. Hui, and J. B. Qiang, "Influence factor analysis of paste filling material strength," Journal of Liaoning Technical University, vol. 25, no. 6, pp. 904-906, 2006.

[28] Z. Li, "Full tailing paste filling in the research and application of Lame zinc mine," Mining Technology, vol. 15, no. 1, pp. 6-13, 2015.

[29] Y. Zhai, A. Wu, and H. Wang, "Study on rheological properties of the unclassified-tailings paste," Metal Mine, vol. 39, no. 12 , pp. $30-32,2010$.

[30] A. Wu, H. Jiao, and H. Wang, "Yield stress measurements and optimization of paste tailings," Journal of Central South University (Science and Technology), vol. 8, pp. 3370-3376, 2013.

[31] A. Wu, "Review on paste filling with tailings disposal technology," Mining Equipment, vol. 36, no. 4, pp. 32-35, 2011.

[32] H. Wang, A. Wu, and J. Chen, "Full tailings-slag paste material pumping index optimization," Mining Technology, vol. 7, no. 3, pp. 15-17, 2007.

[33] Z. A. Glaser, J. A. Fougerousse, S. J. Galgano et al., "Highvolume concurrent polypoid ureteritis and ureteritis cystica manifesting with ureteral obstruction," Urology, vol. 136, 2020.

[34] M. Benzaazoua, M. Fall, and T. Belem, "A contribution to understanding the hardening process of cemented pastefill," Minerals Engineering, vol. 17, no. 2, pp. 141-152, 2004.

[35] W. S. Aaron, M. J. Hamlin, and P. S. Surendra, "A generalized approach for the determination of yield stress by slump and slump flow," Cement and Concrete Research, vol. 34, no. 3, pp. 363-371, 2004.

[36] S. Kwan, J. LaRosa-Thompson, and M. W. Grutzeck, "Structures and phase relations of aluminum-substituted calcium silicate hydrate," Journal of the American Ceramic Society, vol. 79, no. 4, p. 967, 1996.

[37] J. Rutqvist, “Thermal management associated with geologic disposal of large spent nuclear fuel canisters in tunnels with thermally engineered backfill," Tunnelling and Underground Space Technology Incorporating Trenchless Technology Research, vol. 102, Article ID 103454, 2020.

[38] P. M. Keeley, N. A. Rowson, T. P. Johnson, and D. E. Deegan, "The effect of the extent of polymerisation of a slag structure on the strength of alkali-activated slag binders," International Journal of Mineral Processing, vol. 164, p. 37, 2017.

[39] S. Clayton, T. G. Grice, and D. V. Boger, "Analysis of the slump test for on-site yield stress measurement of mineral suspensions," International Journal of Mineral Processing, vol. 70, no. 1-4, pp. 3-21, 2003.

[40] B. Ercikdi, H. Baki, and M. Izki, "Effect of desliming of sulphide-rich mill tailings on the long-term strength of cemented paste backfill," Journal of Environmental Management, vol. 115, pp. 5-13, 2013.

[41] H. Alhassan, P. Adjei Kwakwa, and E. Owusu-Sekyere, "Households' source separation behaviour and solid waste disposal options in Ghana's Millennium City," Journal of Environmental Management, vol. 259, 2020.
[42] F. W. Brackebusch, "Basics of paste backfill systems," Mining Engineering, vol. 46, no. 10, pp. 1175-1178, 1994.

[43] M. A. Khairul, J. Zanganeh, and B. Moghtaderi, "The composition, recycling and utilisation of Bayer red mud," Resources, Conservation and Recycling, vol. 141, p. 483, 2019.

[44] S. K. Nath and S. Kumar, "Role of particle fineness on engineering properties and microstructure of fly ash derived geopolymer," Construction and Building Materials, vol. 233, Article ID 117294, 2020.

[45] P. Kandiah and S. Nagaratnam, "Arching within hydraulic fill stopes," Geotech Geological Engineering, vol. 25, no. 1, pp. 25-35, 2007.

[46] D. F. Mccarthy, Essentials of Soil Mechanics and Foundations: Basic Geotechnics, Prentice-Hall, Upper Saddle River, NJ, USA, 1998.

[47] M. Aubertin, L. Li, and S. Arnoldi, "Interaction between backfill and rock mass in narrow stopes," Soil and Rock Mechanics America, vol. 2, pp. 1157-1164, 2003.

[48] L. Li, M. Aubertin, and T. Belem, "Formulation of a three dimensional analytical solution to evaluate stresses in backfilled vertical narrow openings," Canadian Geotechnical Journal, vol. 42, no. 5, pp. 1705-1717, 2005.

[49] L. Li and M. Aubertin, "An improved analytical solution to estimate the stress state in subvertical backfilled stopes," Canadian Geotechnical Journal, vol. 45, no. 10, pp. 1487-1496, 2008. 